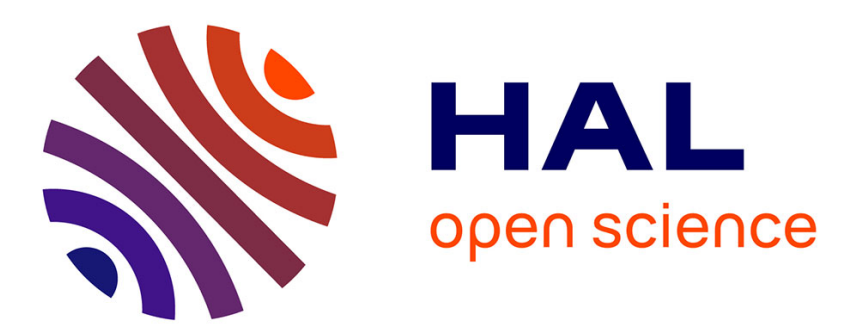

\title{
Biocompatibility and osseointegration of nanostructured titanium dental implants in minipigs
}

Alain Hoornaert, Luciano Vidal, Romain Besnier, Jean-francois Morlock, Guy Louarn, Pierre Layrolle

\section{- To cite this version:}

Alain Hoornaert, Luciano Vidal, Romain Besnier, Jean-francois Morlock, Guy Louarn, et al.. Biocompatibility and osseointegration of nanostructured titanium dental implants in minipigs. Clinical Oral Implants Research, In press, 10.1111/clr.13589 . hal-02553588

\section{HAL Id: hal-02553588 \\ https://hal.science/hal-02553588}

Submitted on 30 Apr 2020

HAL is a multi-disciplinary open access archive for the deposit and dissemination of scientific research documents, whether they are published or not. The documents may come from teaching and research institutions in France or abroad, or from public or private research centers.
L'archive ouverte pluridisciplinaire HAL, est destinée au dépôt et à la diffusion de documents scientifiques de niveau recherche, publiés ou non, émanant des établissements d'enseignement et de recherche français ou étrangers, des laboratoires publics ou privés. 


\title{
Biocompatibility and osseointegration of nanostructured titanium dental implants in minipigs
}

\author{
Alain Hoornaert ${ }^{1,2}$ | Luciano Vidal ${ }^{1}$ | Romain Besnier ${ }^{1}$ | Jean-Francois Morlock ${ }^{1}$ | \\ Guy Louarn $^{3}$ | Pierre Layrolle ${ }^{2}$ (D)
}

${ }^{1}$ Department of Oral Implantology, Faculty of Dental Surgery, CHU Nantes, Nantes, France

${ }^{2}$ Inserm, UMR 1238, PHY-OS, Bone Sarcomas and Remodeling of Calcified Tissues, Faculty of Medicine, University of Nantes, Nantes, France

${ }^{3}$ Institut des Matériaux Jean Rouxel (IMN), CNRS, University of Nantes, Nantes, France

Correspondence

Pierre Layrolle, Inserm, UMR 1238, PHY-OS, Bone Sarcomas and Remodeling of Calcified Tissues, Faculty of Medicine, University of Nantes, 1 Rue Gaston Veil, 44035 Nantes, France.

Email: pierre.layrolle@inserm.fr

Funding information

Biotech Dental

\begin{abstract}
Objectives: It is well known that surface treatments of dental implants have a great impact on their rate of osseointegration. The aim of this study was to compare the biocompatibility and the bone-implant contact (BIC) of titanium dental implants with different surface treatments.

Material and methods: Test implants (Biotech Dental) had a nanostructured surface and control implants (Anthogyr) were grit-blasted with biphasic calcium phosphate and acid-etched surface. Both titanium implants were inserted in mandible and maxillary bones of 6 Yucatan minipigs for 4 and 12 weeks ( $n=10$ implants/group). Biocompatibility and osseointegration were evaluated by non-decalcified histology and back-scattered electron microscopy images.

Results: The reading of histology sections by an antomo-pathologist indicated that the test implants were considered non-irritating to the surrounding tissues and thus biocompatible compared with control implants. The BIC values were higher for test than for control dental implants at both 4 and 12 weeks.

Conclusions: In summary, the new nanostructured titanium dental implant is considered biocompatible and showed a better osseointegration than the control implant at both 4 and 12 weeks.
\end{abstract}

KEYWORDS

dental implants, nanostructured surface, osseointegration

\section{1 | INTRODUCTION}

The replacement of lost teeth with dental implants has become a standard practice in clinics over the last few decades. The osseointegration of implants is a complex process in which the implant surface plays a leading role (Le Guéhennec, Soueidan, Layrolle, \& Amouriq, 2007). Favorable rough surfaces for osseointegration usually presented irregularities with arithmetic mean roughness parameters ( $\mathrm{Ra}$ or Sa) that are around to 1-2 $\mu \mathrm{m}$ and a developed surface area ratio (Sdr) raising 50\% (Wennerberg \& Albrektsson, 2000, 2010). Most dental implants have a rough surface obtained by grit blasting with alumina particles $\left(\mathrm{Al}_{2} \mathrm{O}_{3}\right)$ and acid etching $\left(\mathrm{H}_{2} \mathrm{SO}_{4} / \mathrm{HNO}_{3}\right)$ to ensure a good biomechanical anchoring in the bone tissue. However, contamination of the titanium implant surface by alumina particles is often observed and decreases the biocompatibility and osseointegration of the implants (Balshe, Assad, \& Oral, 2009; Doundoulakis, 1987; Kim, Koak, Chang, Wennerberg, \& Heo, 2003; Mathieu et al., 2006; Müeller et al., 2003; Piattelli, Manzon, Scarano, Paolantonio, \& Piattelli, 1998; Rodríguez-Hernández, Juárez, Engel, \& Gil, 2011; Yurttutan \& Keskin, 2018). 
Calcium phosphate biomaterials, in particular hydroxyapatite (HA) beta-tricalcium phosphate (TCP) and mixtures, so named biphasic calcium phosphate (BCP), are constituents of the bone mineral and thus, biocompatible. These materials are well known to form a direct bond with surrounding bone tissue after implantation. For several decades, these biomaterials, sintered at high temperature with organic pore makers, have been used as synthetic porous bone fillers. Plasma-sprayed HA coating has also shown to greatly enhance the early osseointegration and long-term success rate of titanium orthopedic prosthesis. In view of these favorable osteoconductive properties, calcium phosphate particles could be used for roughening the surface of dental implants by grit blasting. Furthermore, calcium phosphate materials are fully soluble in acids and a simple acid etching in diluted $\mathrm{HNO}_{3}$ has been shown to eliminate most entrapped particles from the titanium surface after grit blasting (Citeau et al., 2005). This new method of grit blasting with calcium phosphate particles has been shown to increase the arithmetic mean height on roughness profiles $(\mathrm{Ra})$ of machined titanium implants from $0.58 \pm 0.05$ to $1.57 \pm 0.07 \mu \mathrm{m}$ (Citeau et al., 2005). Furthermore, X-ray photoelectron spectroscopy (XPS) has indicated traces of calcium and phosphorus on BCP grid-blasted titanium surfaces after diluted acid etching. This new grid-blasting process not only increased the surface roughness of titanium implants but also offered a non-cytotoxic surface with regard to osteoblastic cells. Nevertheless, only very limited in vivo studies have compared the biocompatibility and osseointegration of these new surfaces of dental implants in a relevant animal model whereas the minipigs mandible's model is widely described in the literature for testing dental implants (Lin, Wang, Kelly, Gubbi, \& Nishimura, 2009; Poulos et al., 2011).

This study aims to evaluate the biocompatibility and osseointegration of a new surface treatment in comparison with a comparable surface on dental implants. In the test group (Kontact $\mathrm{N}$, Biotech Dental), the implants were first grit-blasted by using BCP ceramic particles for micro-roughening and then acid etched for nano-structuring of the surface. The control implant surface (Axiom ${ }^{\circledR}$, Anthogyr) was obtained by subtractive grit blasting with BCP ceramic particles and acid etching. The hypothesis of the study is that nanometer features may affect the osseointegration of dental implants. Both surfaces of dental implants were first characterized in terms of roughness, scanning electron microscopy and XPS. These dental implants (control and test) were implanted bilaterally under general anesthesia at the mandibular and maxillae levels in minipigs. After 4 and 12 weeks, both the biocompatibility and the bone-implant contact $(\mathrm{BIC})$ were evaluated by histology and by back-scattered scanning electron microscopy.

\section{2 | MATERIAL AND METHODS}

\section{1 | Dental implants}

Two types of dental implants were used in this study. Axiom ${ }^{\circledR}$ implants were supplied by Anthogyr, Sallanches, France and Kontact $\mathrm{N}$ dental implants were provided by Biotech Dental, Salon de Provence,
France. Both types of dental implants were machined out of Grade $\mathrm{V}$ titanium alloy (Ti6Al4V). Axiom ${ }^{\circledR}$ implants, $3.4 \mathrm{~mm}$ in diameter and $8 \mathrm{~mm}$ in length with BCP surface treatment applied by subtractive grit blasting and acid etching, were considered as CONTROL. Kontact $\mathrm{N}$ dental implants $3.6 \mathrm{~mm}$ in diameter and $8 \mathrm{~mm}$ in length were grit-blasted with BCP ceramic particles for micro-roughening and then acid etched for nano-structuring of the implant surface. Kontact $\mathrm{N}$ dental implants were named TEST.

\subsection{Physico-chemical characterization of surfaces}

The surfaces of the implants were observed with a field emission scanning electron microscope (FE-SEM, JEOL 7600F). Images were obtained from the secondary electron detector with a $5 \mathrm{kV}$ electron beam energy and without further conductive layer on the specimen at the "Centre de microcaractérisation, Institut des Matériaux Jean Rouxel, Université de Nantes."

Surface roughness measurements were performed in the micrometer range by using interferometric optical imaging mode with the instrument Sensofar Neox. The surface analyzed was $255 \times 191 \mu \mathrm{m}$ with a measuring step of $0.3 \mu \mathrm{m}$ on 3 areas of the implants. The average surface roughness ( $\mathrm{Sa}$ ) was expressed as mean \pm SD.

Atomic force microscopy (AFM) images were taken by using the intermittent contact mode (Nanoscope $\mathrm{V}$, Multimode 8 , Bruker). The surface analyzed was $5 \times 5 \mu \mathrm{m}$ with a measuring step of $10 \mathrm{~nm}$ on 3 areas of the dental implants. Classical silicon cantilevers were used (NCLR AFM, Nanosensors ${ }^{\mathrm{TM}}$ ). The average force constant and resonance were approximately $46 \mathrm{~N} / \mathrm{m}$ and $194 \mathrm{kHz}$, respectively. The AFM image processing was done using the Gwyddion V2.49 program which allows, among others, determination of the surface roughness in the nanometer range. The data obtained from the AFM microscope were first leveled with a plane, and then, a second order polynomial function was applied. If applying a filter can be very useful, the actual measured data will be altered during the process. Special care has therefore been taken to avoid destroying important nanofeatures of the image. When analyzing the surface roughness of the samples, several representative parameters have been selected: the mean roughness $(R a)$, the mean square roughness $(R q)$, the surface skewness (Rsk) and the kurtosis coefficient (Rku). Ra was used to represent the mean value of the surface roughness whereas the mean square roughness is used to represent the degree of change in the surface roughness. The surface skewness was used to represent the symmetry of the surface height distribution, and the kurtosis coefficient was used to represent the waveform characteristics of the surface height distribution.

X-ray photoelectron spectroscopy was carried out at room temperature with an Axis Nova spectrometer from Kratos Analytical with $\mathrm{Al} \mathrm{K \alpha}$ line $(1,486.6 \mathrm{eV})$ as the excitation source. Implants were directly introduced under vacuum overnight in the sample exchange chamber of the spectrometer after opening the commercial packaging. It is well known that carbonaceous atmospheric 
contamination on Titania usually occurs quickly. However, no surface cleaning such as using ion sputtering was done to avoid changes in the chemical composition and structural damages. Finally, data analysis and quantifications were performed by using the Casa XPS software.

\section{3 | Ethical approval of the animal study}

Ethical approval for all animal experimentation was obtained from the local ethical committee (CEEA19, Val de Loire, France; Authorization \#7365 dated on 5/01/2017) in accordance with the European Guidelines for Animal Care directive 2010/63/EU. This study conformed with the ARRIVE Guidelines. Six female Yucatan minipigs with an age of 18 months (body weight $>40 \mathrm{~kg}$ ) were supplied by a professional breeder (INRA UE PR 1,421) and delivered to the experimental surgery facility (INRA, CIRE). The animals were housed by 2 in 3 boxes littered with straw in a ventilated and air-conditioned at $20 \pm 1^{\circ} \mathrm{C}$ room with natural day/night cycle. They were observed and fed every day with a soft diet for minipigs and water ad libitum. The animals were acclimated for 2 weeks and fasted overnight prior to surgery. Following surgeries, they were observed daily for behavior, food and water normal intake and received appropriate analgesia and antibiotic prophylaxis as described below.

\section{4 | Surgery}

The study was carried out on 6 female Yucatan Minipigs in two surgical phases. The surgeries were performed under aseptic conditions in an animal operating theater under general anesthesia. Prior to surgery, all animals were fasted overnight to prevent vomiting. On the day of surgery, minipigs were pre-medicated with a sub-cutaneous injection of Xylazine (1 mg/kg IM, Rompun 2\%; Bayer), Ketamine (10 mg/kg IM, Imalgène 1,000, 100 mg/ml; Merial) and Morphine $(0.5 \mathrm{ml}$ IM Morphine $20 \mathrm{mg} / \mathrm{ml}$; Lavoisier). The minipigs were placed on their back on the surgical table, orotrachea intubated and maintained under general anesthesia with a mixture of isoflurane/oxygen ( $2 \% / 20 \%)$. Animals were fully monitored for heart pulse, breathing frequency, oxygen saturation and body temperature during surgery. The mouth was maintained open and disinfected with povidone iodine. Sterile surgical drapes were placed. Local anesthesia was provided at the beginning of each surgery by an infiltrative injection of 1-3 doses of $1.8 \mathrm{ml}$ of Articaïne/adrenaline (Alphacaïne; Dentsply).

In the first phase, bilateral extraction of the mandibular and maxillary teeth (premolars 1-4 and first molar) was performed. Gingiva incisions were performed, and the teeth were separated by means of a diamond bur mounted on a contra-angle (MIO MR320, NSK). Dental ligament was disrupted using a root elevator, and tooth was then extracted with forceps. After tooth extraction, the alveolar sockets were thoroughly rinsed with saline solution and full closure of the wound was achieved by using mattress resorbable sutures (Monocryl 4/0, Ethicon; Johnson \& Johnson). The absence of dental root remnants was controlled by computed tomography (CT Scan; Somatom ${ }^{\circledR}$, Siemens). The alveolar sockets were allowed to heal for 12 weeks prior to insert the dental implants.

In a second surgery, after 12 weeks of healing, 10 dental implants per minipig (5 CONTROL and 5 TEST dental implants) were placed bilaterally in mandible $(n=3 \times 2)$ and maxilla $(n=2 \times 2)$ under general anesthesia. The CONTROL and TEST implants were either placed on the left or right side according to a pre-defined implantation scheme. A mid-crestal incision was performed, and full-thickness buccal and lingual flaps were raised. Three implants were placed into the posterior area on both sides of the mandible with an inter-implant distance of $4 \mathrm{~mm}$ and two implants were placed into the posterior area on both side of the maxillae according to the drilling sequence and insertion torque of $35 \mathrm{Nm}$ as recommended by the manufacturer. All implants received standard healing caps (closure screws), and the flaps were sutured (Monocryl 4/0, Ethicon). The sites were allowed to heal for 4 or 12 weeks prior to sacrifice.

After teeth extraction and dental implants placement, post-operative analgesia was conducted at extubation with transdermal patch of Fentanyl (Durogesic $100 \mu \mathrm{g} / \mathrm{hr}$ Janssen-Cilag), intramuscular injection of Morphine ( $0.5 \mathrm{ml}$ Morphine $20 \mathrm{mg} / \mathrm{ml}$, Lavoisier) and intramuscular injection of $2 \mathrm{ml}$ Flunixine (Finadyne $50 \mathrm{mg} / \mathrm{ml}$; MDS Santé Animale). If necessary, injection of $3 \mathrm{ml}$ Dopraxam (Dopram ${ }^{\circledR}$, Vetoquinol) was performed to stimulate respiratory rate after anesthesia. Post-operative antibiotic prophylaxy (Tenaline $20 \mathrm{mg} / \mathrm{kg} \mathrm{IM}$, Ceva, batch no 110ZA8) was administrated at extubation and every $48 \mathrm{hr}$ for 1 week. All minipigs recovered well from surgery; no other post-operative analgesia was needed as none of the minipigs show sign of pain.

Two groups of 3 minipigs were sacrificed at 4- and 12-week post-implantation, respectively. Animals were sedated by intramuscular injection of Xylazine (Rompun 2\%; Bayer) and ketamine (Imalgène $100 \mathrm{mg} / \mathrm{ml}$; Merial). Euthanasia was conducted by inducing respiratory and cardiac arrest with an intravenous injection of an overdose of pentobarbital solution ( $5 \mathrm{ml}$, Doléthal, Vétoquinol). The mandible and maxilla sites of implantation were dissected and immediately fixed in ten volumes of $4 \%$ formalin. After fixation, the mandible and maxilla were cross-sectioned around the dental implants by using diamond saw and numbered. Samples were then processed for non-decalcified histology.

\section{5 | Histology}

After fixation for 7 days, the specimens were rinsed in water, dehydrated in a graded series of ethanol (from $70 \%$ to $100 \%$ ), impregnated in methyl methacrylate and finally embedded in poly-methyl methacrylate (PMMA) resin. Polymerization was performed by adding a radical initiator and propagator under vacuum at $4^{\circ} \mathrm{C}$ in order to prevent the formation of bubbles. After resin hardening, each 
implant was longitudinally sectioned in the middle with a diamond circular saw (Leica SP1600). A half block was then mounted onto a glass slide, and serial sections of $10 \mu \mathrm{m}$ thickness were generated by using an ultra-fast laser cutting system enabling precise, non-contact processing of specimens (TissueSurgeon, LLS Rowiak). Hematoxylin-Eosin-Safran (HES), Masson's Trichrome and Mc Neal (toluidine blue/basic fuchsine) staining of thin sections of mandibular and maxillary explants were obtained according to standard operating procedures. Stained slices were digitalized using high-resolution scanner (NanoZoomer 2.0; Hamamatsu Photonics) in bright field conditions with the objective $\times 20$ and $5 \mathrm{Z}$ stacks and viewed with a virtual microscope (NDP view; Hamamatsu).

\section{6 | Biocompatibility of implants}

The local effects after implantation at 4 and 12 weeks were evaluated semi-quantitatively by an experienced anatomo-pathologist by using the objective score system provided in NF EN ISO 109936:2009 standard: Biological evaluation of medical devices-Part 6: Tests for local effects after implantation; Annex E. The inflammation was assessed by analysis of the cellular populations of polynuclear cells, lymphocytes, plasmocytes, macrophages and giant cells and tissue necrosis while local tissue response was examined through neovascularization, fibrosis and fat infiltration scoring. The scores were then reported in the test sample evaluation form that allowed to compare the TEST and CONTROL implants to each other on various histological levels. Comparisons between CONTROL and TEST implant sites in 2 minipigs at each implantation time of 4 and 12 weeks ( $n=10$ implants per group and delay) allowed to judge about the biocompatibility of the TEST implants.

\section{7 | Osseointegration of implants}

Poly-methyl methacrylate resin embedded blocks with implants was longitudinally sectioned in the middle of the implant with a diamond circular saw (Leica SP1600). Each half remaining blocks were polished and observed by back-scattered electron microscopy (BSEM; Tabletop TM3000, Hitachi) in order to quantify the osseointegration the CONTROL and TEST implants. Contiguous BSEM images of the whole implant and surrounding bone tissue were taken at a magnification of $\times 50$ by using a motorized programmable stage (Debel). On these BSEM images, the titanium implant appeared in light gray, mineralized bone in gray and non-mineralized tissue in black. Histomorphometry was carried out by using a custom-made program developed with the image processing software (ImageJ). On each image, the percentage of direct contact between the mineralized bone and titanium surface (BIC) was calculated by using a semi-automatic binary treatment. The newly formed bone surface at a distance of $0.5 \mathrm{~mm}$ around the implant (BS/TS $0.5 \mathrm{~mm}$ ) was also measured as previously described (Salou, Hoornaert, Louarn, \& Layrolle, 2014).

\section{8 | Statistics}

All data collected were presented as mean $\pm S D$. Comparisons of biocompatibility and osseointegration (BIC, BS/TS) between CONTROL and TEST implants were performed at each implantation time of 4 and 12 weeks ( $n=10$ implants per group). Statistical analysis was performed using the paired Student $t$ test using Graphpad, Prism 6.0 software. $p$-Values $<.05$ were considered statistically significant.

\section{3 | RESULTS}

\section{1 | Physico-chemical characterization of surfaces}

Scanning electron microscope images of the surfaces of dental implants are shown in Figure 1. At low magnification, implants exhibited a rough surface with irregular shaped depressions for CONTROL and rounded cavities for TEST surfaces, respectively. This microtopography was quantitatively evaluated by interferometric optical microscopy (Table 1). It should be stressed here that the micro-roughness of the TEST samples ( $\mathrm{Sa} \approx 2.0 \mu \mathrm{m}$ ) was twice that of the CONTROL samples ( $\mathrm{Sa} \approx 1.2 \mu \mathrm{m}$ ). However, at higher magnification, the nanoscale topography was radically different. For instance, pits of about $70 \mathrm{~nm}$ were observed on the CONTROL surface while needle-like crystals of approximately $150 \mathrm{~nm}$ in length covered the TEST surface. These observations were corroborated by surface roughness measurements performed by AFM and reported in Table 1. AFM measurements indicated Ra values in the range of 132 and $69 \mathrm{~nm}$, corresponding to pits and needle-like crystals of TEST and CONTROL surfaces, respectively.

The surface composition of the different implants was determined by XPS, and atomic percentages were reported in Table 1. In both groups, the Titanium alloy surface was oxidized as titanium oxide and polluted with nitrogen and silicon probably resulting from the chemical etching, cleaning and grit-blasted processes. Interestingly, calcium and phosphorus were found on the TEST surface. The relative amount of calcium and phosphorus $163 \%$ and $37 \%$, respectively) was in good agreement with the chemical composition of HA/ B-TCP or BCP particles used for grit blasting. This observation tended to confirm that the nanostructures present on the surface of the TEST implants, corresponded to the biocompatible materials as HA and B-TCP. Conversely, the surfaces of the CONTROL specimens presented some contaminants such as alumina and silica that are not known as favorable for osseointegration.

\section{2 | Biocompatibility and osseointegration of dental implants}

All animals survived the two surgeries of teeth extraction and dental implantations with normal uptake of food during the course 

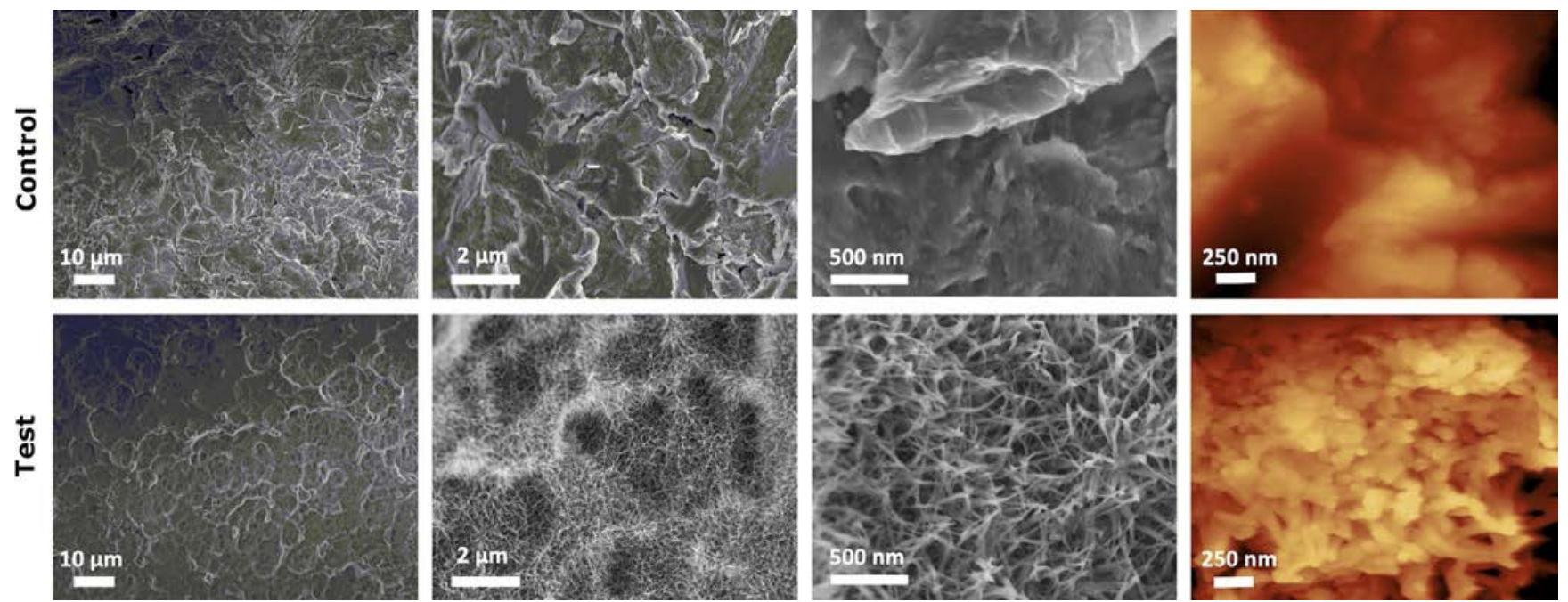

FIGURE 1 Scanning electron microscope and atomic force microscopy images of CONTROL and TEST dental implant surfaces at magnifications of $\times 1,300, \times 10,000, \times 50,000$ and $\times 100,000$

TABLE 1 Physico-chemical characterization of the TEST and CONTROL surfaces of dental implants

\begin{tabular}{|c|c|c|c|c|c|c|c|c|c|}
\hline \multirow[b]{2}{*}{ Group } & \multirow[b]{2}{*}{ Manufacturer } & \multicolumn{8}{|c|}{ Surface Roughness } \\
\hline & & $\mathrm{Sa}(\mu \mathrm{m})(\mathrm{a})$ & $\mathrm{Ra}(\mathrm{nm})(\mathrm{b})$ & $\mathrm{Rq}(\mathrm{nm})(\mathrm{b})$ & $\mathrm{Rk}(\mathrm{nm})(\mathrm{b})$ & Rsk (nm) (b) & $\operatorname{RSm}(\mathrm{nm})(\mathrm{b})$ & $R \Delta q(\%)(b)$ & Sdr (\%) \\
\hline \multirow[t]{2}{*}{ CONTROL } & Anthogyr & $1.18 \pm 0.06$ & $132 \pm 20$ & $172 \pm 20$ & 0.29 & 0.095 & 635 & 37 & $28 \pm 6$ \\
\hline & & \multicolumn{8}{|c|}{ Atomic surface quantification (\%) (c) } \\
\hline TEST & Biotech Dental & 16.2 & 70.0 & & 4.3 & 5.2 & - & 2.7 & 1.6 \\
\hline CONTROL & Anthogyr & 13.1 & 63.1 & & 10.5 & 9.3 & 2.8 & - & 1.2 \\
\hline
\end{tabular}

Note: (a) Measured by optical interferometry; (b) from atomic force microscopy measurements; and (c) from X-ray photoelectron spectroscopy analysis.

Abbreviations: Ra, arithmetic mean deviation; Rk, the skewness of the profile; Rq, root mean square slope of the assessed profile (hybrid parameter); Rsk, the kurtosis skewness of the profile; RSm, mean spacing of profile elements (spatial parameter); R $\Delta \mathrm{q}$, the root mean square deviation; Sa,

arithmetic mean deviation of the surface; Sdr, developed surface area ratio.

of the study. No peri-operative or post-operative complications were noted. At euthanasia, all implantation sites had a normal aspect without signs of necrotic tissue, inflammation or apparent infection. As shown in Figures 2 and 3, both groups of dental implants appeared well osseointegrated in the mandible and maxillary bones after 4 and 12 weeks. However, the bone surrounding the implants appeared less dense with large trabecular spaces in the maxillary than in the mandible, irrespectively of the groups of implants. Direct bone apposition on the TEST and CONTROL implant surfaces was qualitatively less abundant at 4 weeks than at 12 weeks.

The biocompatibility was evaluated by an anatomo-pathologist, and the results are reported in Table 2. A very limited number of inflammatory cells were observed indicated that both TEST and CONTROL implants were biocompatible. Both the TEST and CONTROL dental implants were considered non-irritating to the surrounding tissues.
The previous histology observations were corroborated by BSEM images shown in Figures 4 and 5 . Mineralized bone tissue was observed in the peri-implant region of both groups. The mandible bone appeared more compact than the maxillary bone that is more trabecular in nature. For both types of implants, bone apposition increased with the healing time of 4 and 12 weeks. Histomorphometry results of $\mathrm{BIC}$ are reported in Figure 6. In mandibles, BIC values averaged $35.7 \% \pm 16 \%$ and $47 \% \pm 10.4 \%$ for TEST at 4 and 12 weeks, respectively, compared to $12.6 \% \pm 3 \%$ and $32.2 \% \pm 21.5 \%$ for CONTROL implants at the same delays. In maxillary, the mean BIC values were $35.9 \% \pm 11.9 \%$ and $21.9 \% \pm 10.9 \%$ for TEST and $21 \% \pm 10.5 \%$ and $20.6 \% \pm 6.5 \%$ for CONTROL at 4 and 12 weeks, respectively. A significant difference was found between BIC values for TEST and CONTROL implants at 4 weeks. As shown in Figure 7, BS/TS values averaged $65 \%$ and $38 \%$ for implants inserted in mandibular or maxillary bones at all delay and whatever the type of implants. The total BS/ TS results were similar for all groups without statistical differences. 


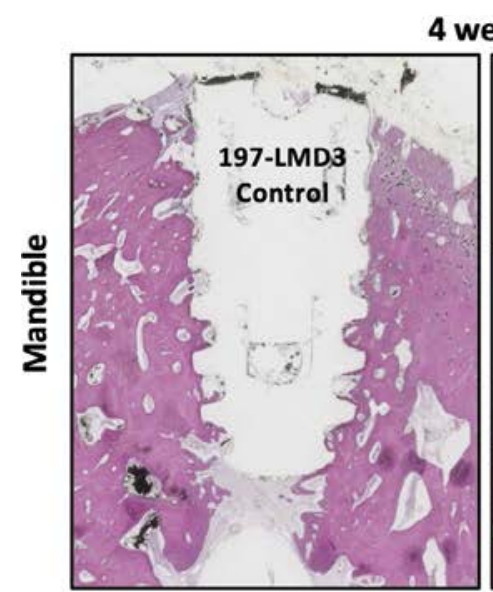

weeks
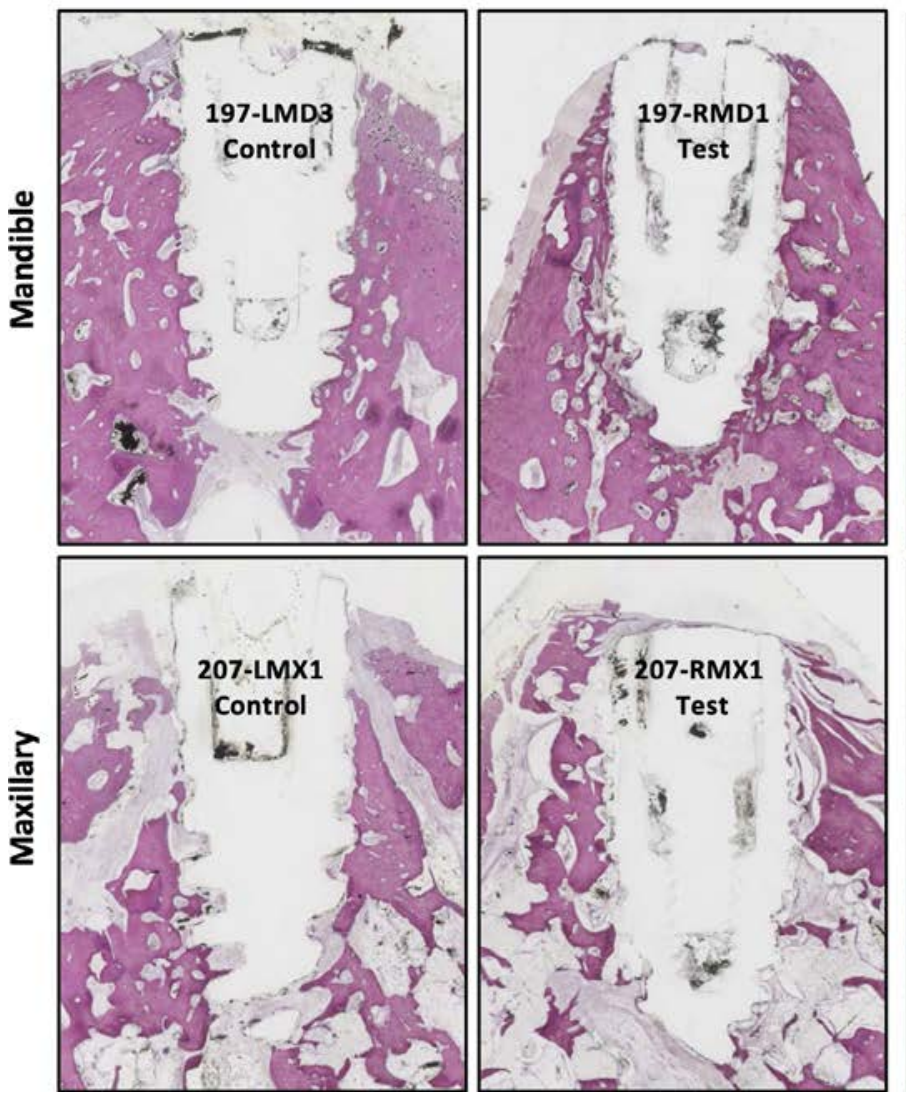
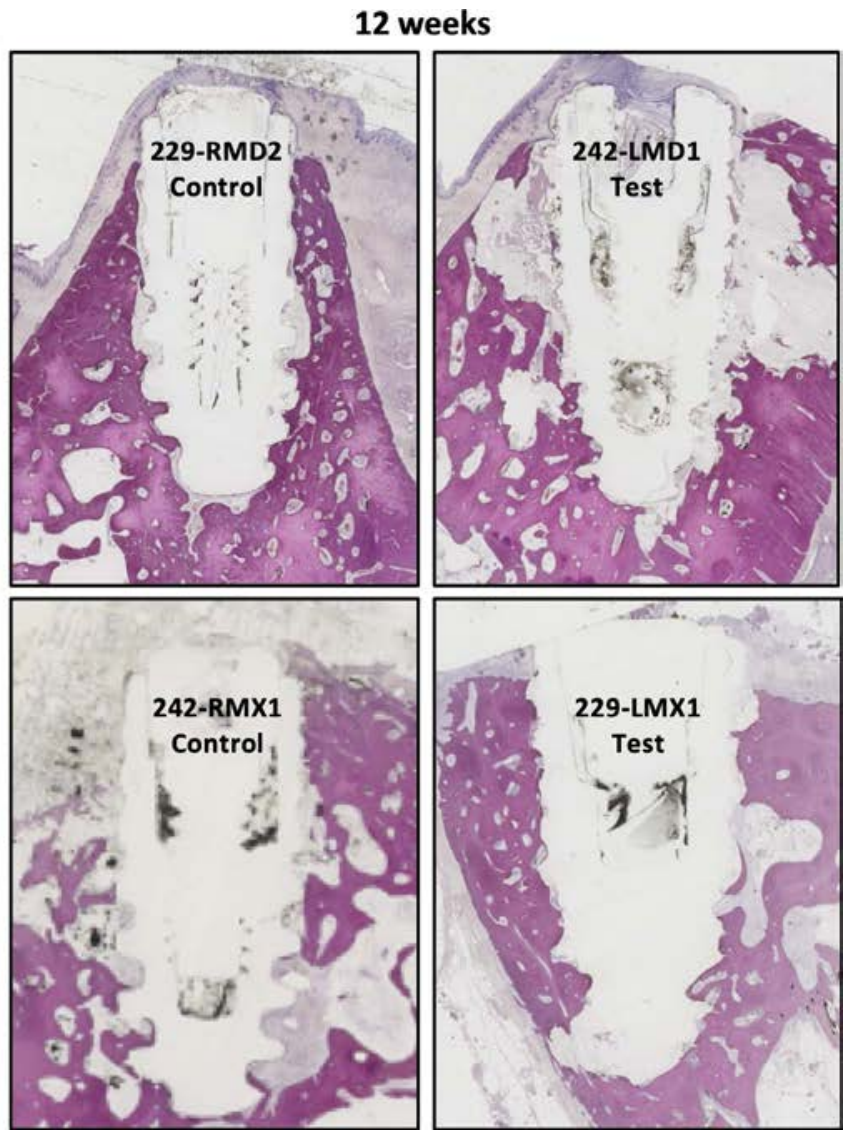

FIGURE 2 Representative histological images of CONTROL and TEST dental implants inserted in mandible and maxillary of minipigs for 4 and 12 weeks (Hematoxylin-Eosin-Safran staining, magnification $\times 1.5$; sample numbering is indicated by the unique tag number for animal and its implantation site Left/Right, Mandible/Maxillae MD/MX, Anterior/Posterior 1,2,3)

\section{DISCUSSION}

This study assessed the biocompatibility and osseointegration of two dental implant systems in a relevant pre-clinical model. In the literature, there are a limited number of studies comparing different dental implants that are used in clinical practices (Alayan, Vaquette, Saifzadeh, Hutmacher, \& Ivanovski, 2017; Deporter, Watson, Pilliar, Chipman, \& Valiquette, 1990; Philipp et al., 2014). Although their dimensions were comparable, the dental implants had different tapered designs that may influence their primary stability and anchoring to bone (McCullough \& Klokkevold, 2017). However, these dental implants have not been loaded with prostheses, and thus, the primary stability could be considered equivalent in this pre-clinical model (Carmo Filho, Marcello-Machado, Castilhos, Del Bel Cury, \& Faot, 2018).

In the last decades, a lot of surface modifications have been developed to enhance the osseointegration of dental implants. Surface treatments used in implantology can be additive (e.g., creating a chemical coating) or subtractive (e.g., removing material without changing the chemical composition of the surface). Among other subtracting or additive methods, the most commonly used was large alumina grit-blasted/acid-etched surfaces. The objective of these surface treatments was to accelerate the osseointegration process by creating small lacunae in the implant surface having sizes in the range of those of the osteoblastic cells thus promoting their osseointegration (Li, Liu, Han, \& Xu, 2001). It has been shown that moderately roughened titanium surfaces surpassed smoother or even rougher surfaces in osseointegration (Andrukhov et al., 2016; Wennerberg \& Albrektsson, 2009). It is generally accepted that micro-rugosity obtained by grit blasting treatments improved the surface roughness for anchoring implants into the bone. For instance, microscopic roughness in the range 1-10 $\mu \mathrm{m}$ has been shown to positively influence bone integration of dental implants (Balshe et al., 2009).

If a rough surface increases bone tissue integration as compared to a non-treated surface, it has also been shown that as proteins present in body fluids interact with implant surfaces in the nanometer range. Several research groups are currently studying the nano-surface approach, producing randomly nano-surfaces such as nano-needle, nano-pits and nano-pores for enhancing the biological integration of implants (Louarn, Salou, Hoornaert, \& Layrolle, 2019; Prasopthum, Cooper, Shakesheff, \& Yang, 2019; Salou et al., 2014, 2015). These nano-modifications may regulate the type, number, spacing and distribution of the focal adhesion ligands of cells on the titanium oxide surface. Consequently, the location and spacing of transmembrane integrins of the adhering cells may result in cytoskeletal tensions of the actin filaments that would change gene 


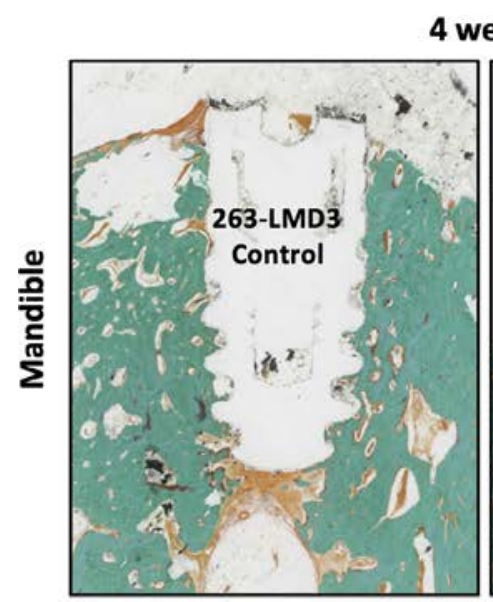

weeks
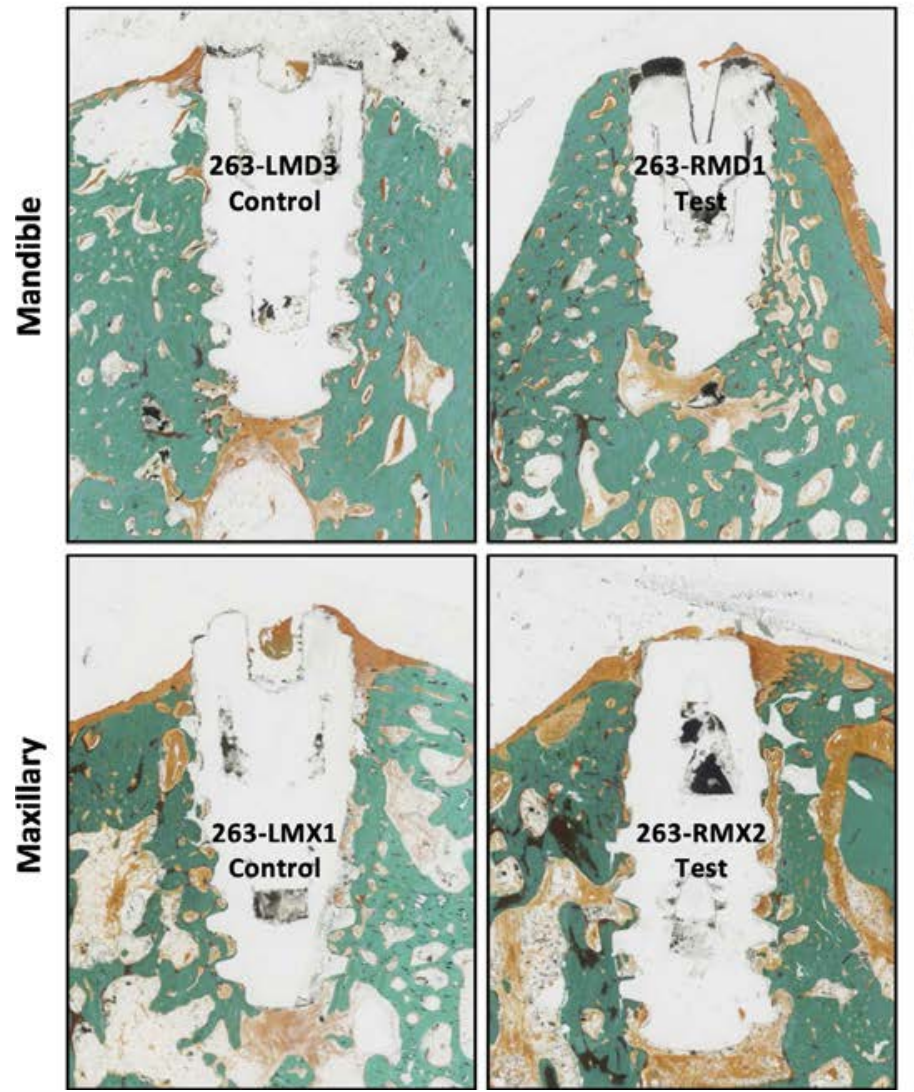

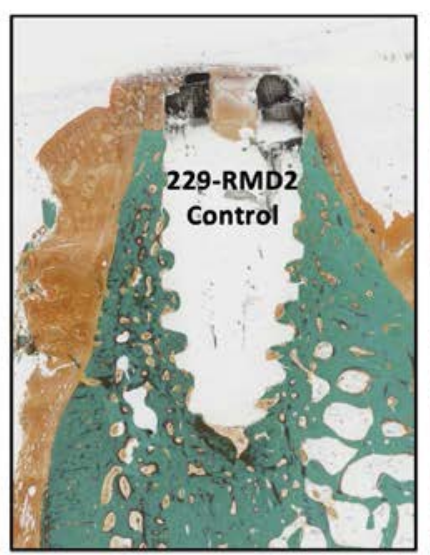

\section{2 weeks}
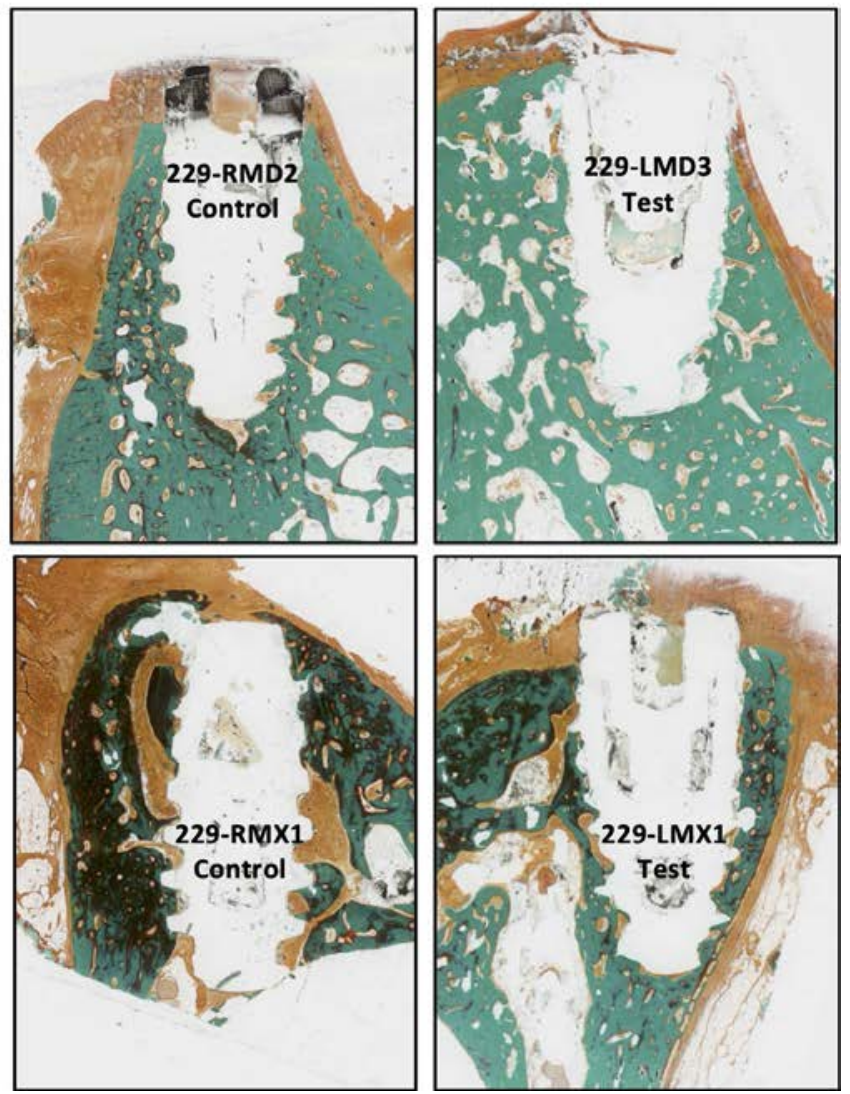

FIGURE 3 Representative histological images of CONTROL and TEST dental implants inserted in mandible and maxillary of minipigs for 4 and 12 weeks (Masson Trichrome staining, magnification $\times 1.5$; sample numbering is indicated by the unique tag number for animal and its implantation site Left/Right, Mandible/Maxillae MD/MX, Anterior-Posterior 1,2,3)

TAB LE 2 Anatomopathology scoring of biocompatibility for the TEST and CONTROL dental implants after 4 and 12 weeks implantations in the mandible and maxillary of minipigs

\begin{tabular}{|c|c|c|c|c|c|c|c|c|}
\hline $\begin{array}{l}\text { Implantation time } \\
\text { Implant } \\
\text { Minipig ID }\end{array}$ & \multicolumn{4}{|c|}{4 weeks } & \multicolumn{4}{|c|}{12 weeks } \\
\hline Polymorphonuclear & 4 & 0 & 1 & 0 & 0 & 0 & 0 & 6 \\
\hline Lymphocytes & 13 & 6 & 14 & 12 & 8 & 5 & 7 & 7 \\
\hline Giant cells & 2 & 0 & 2 & 0 & 2 & 2 & 6 & 3 \\
\hline Necrosis & 4 & 0 & 0 & 0 & 0 & 0 & 0 & 4 \\
\hline Neovascularization & 9 & 4 & 8 & 8 & 5 & 4 & 6 & 5 \\
\hline Fibrosis & 9 & 4 & 7 & 9 & 6 & 6 & 7 & 7 \\
\hline Number of sites & 5 & 4 & 5 & 5 & 5 & 5 & 5 & 5 \\
\hline
\end{tabular}

expression in the cell nucleus and control the proliferation and differentiation of cells in contact to implants. In this study, both types of implants were machined out of titanium alloy and analysis of surfaces revealed that were mainly composed of titanium oxide with traces of other elements (Table 1). Both surfaces were roughened with calcium phosphate particles and acid etched. The two 

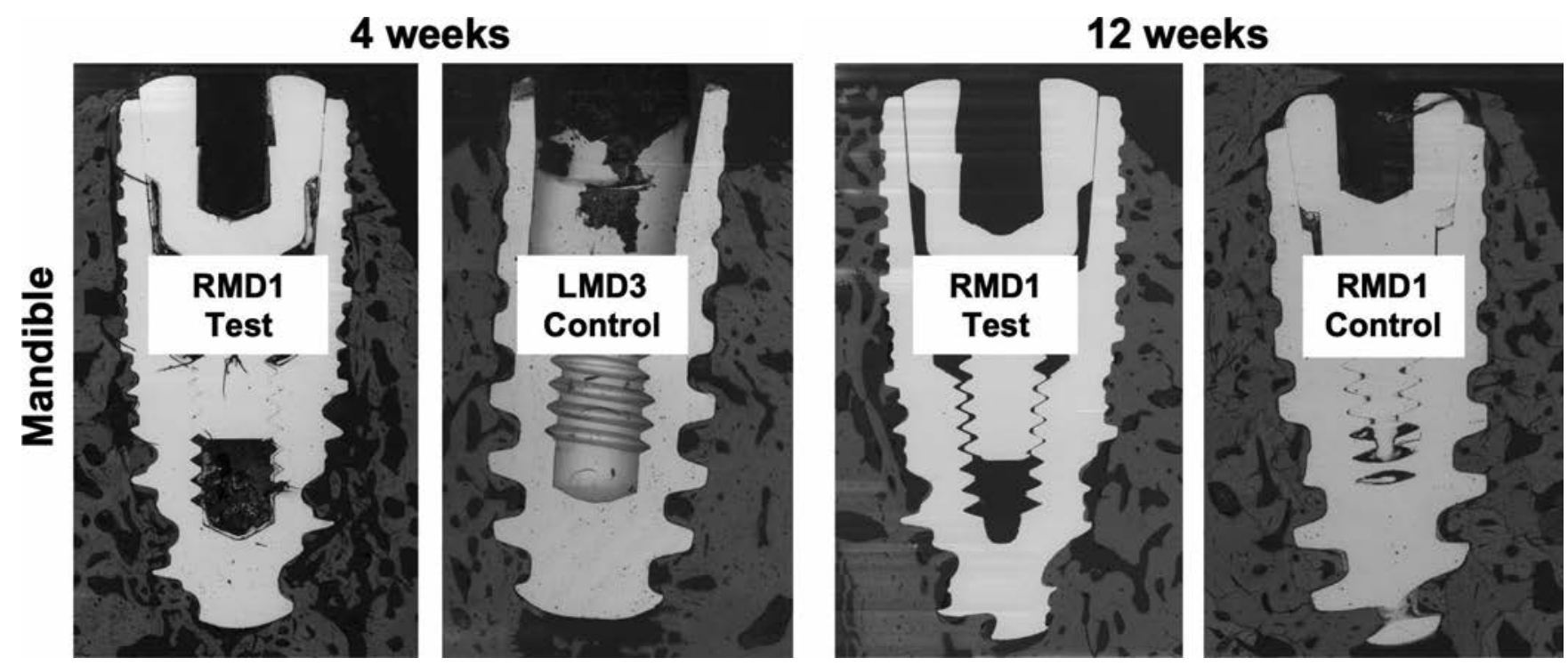

FIGURE 4 Representative BSEM images of CONTROL and TEST dental implants inserted in mandible of minipigs for 4 and 12 weeks (sample numbering is indicated by implantation site Left/Right, Mandible: MD, Anterior-Posterior 1,2,3)
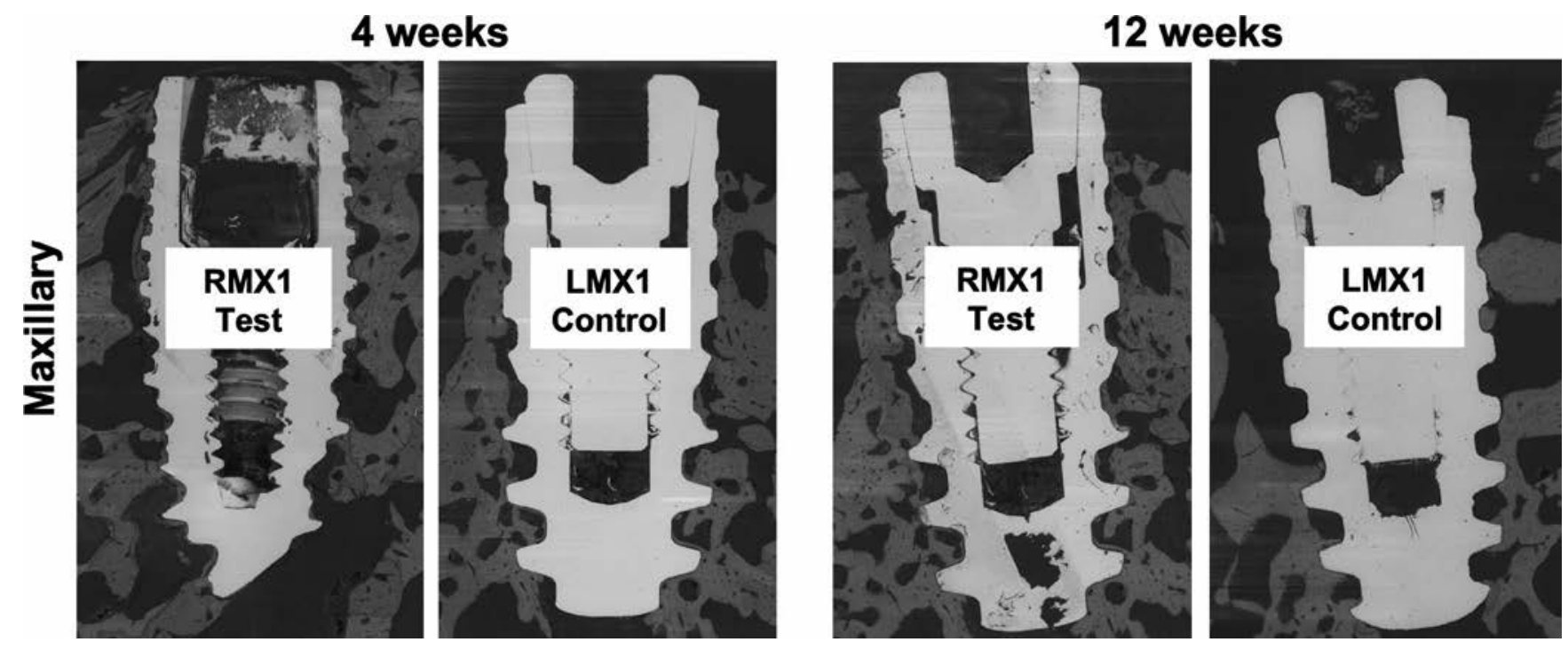

FIGURE 5 Representative BSEM images of CONTROL and TEST dental implants inserted in maxillary of minipigs for 4 and 12 weeks (sample numbering is indicated by implantation site Left/Right, Maxillae: MX, Anterior-Posterior 1,2)

BIC in mandible

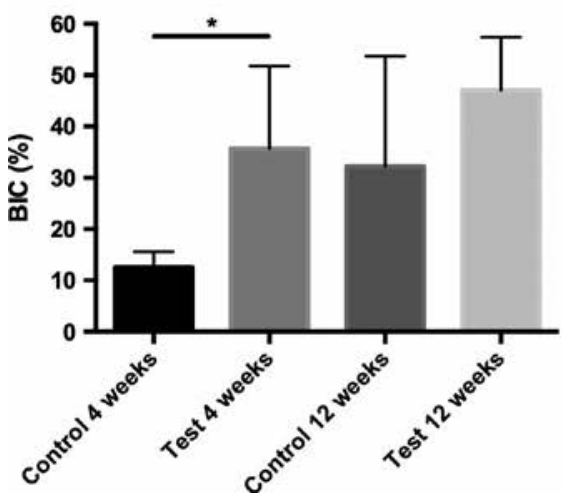

BIC in maxilla

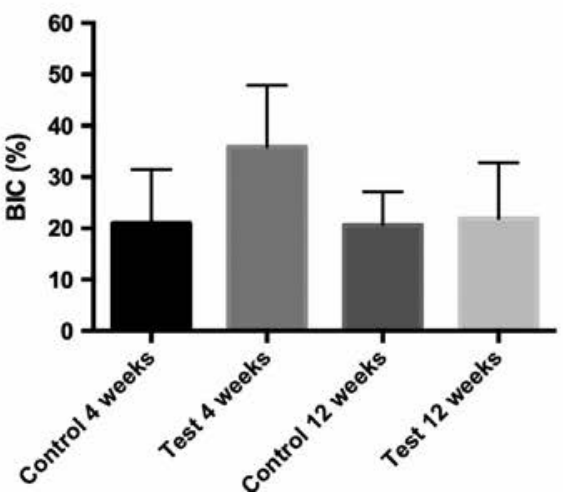

BIC total

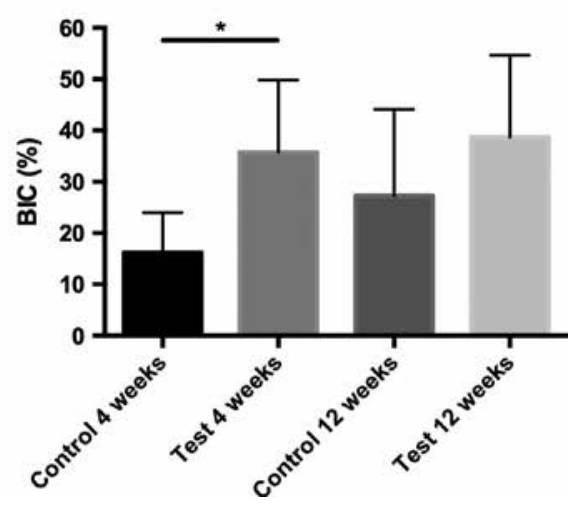

FIGURE 6 Percentages of bone-implant contact (BIC) around the CONTROL and TEST dental implants inserted in mandible and maxillary of minipigs for 4 and 12 weeks $\left({ }^{*} p<.05\right)$ 

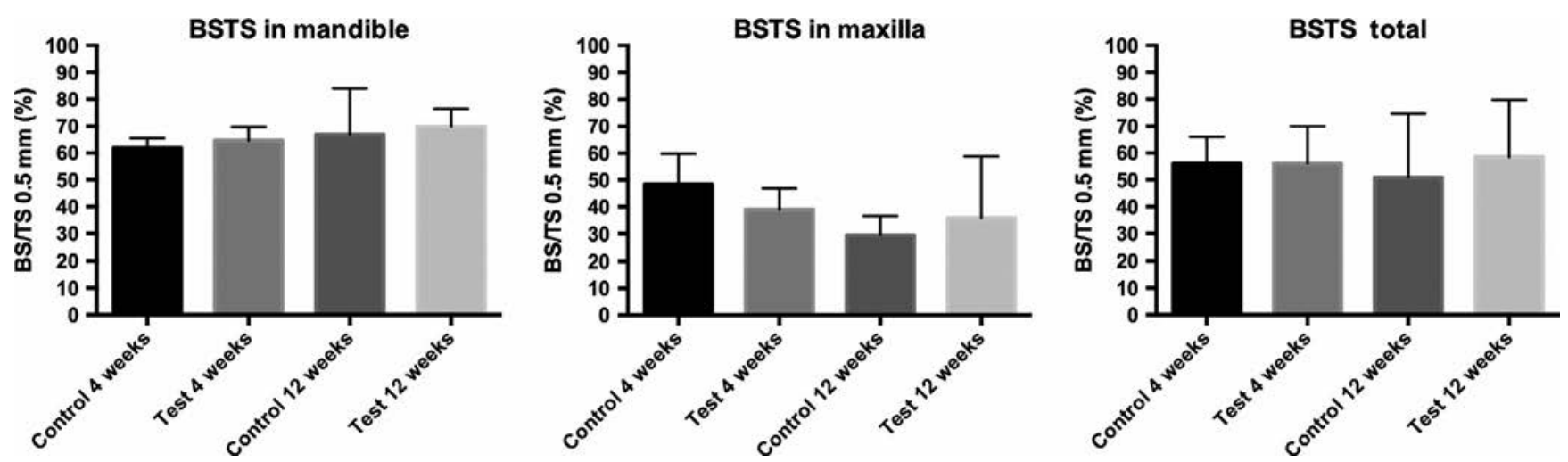

FIGURE 7 Percentages of bone surface/total surface at $0.5 \mathrm{~mm}$ (BS/TS $0.5 \mathrm{~mm}$ ) around the CONTROL and TEST dental implants inserted in mandible and maxillary of minipigs for 4 and 12 weeks

surfaces had similar roughness in the micrometer range but different in morphologies at the nanometer level and corresponds to the criteria of surface topologies previously described to promote osseointegration.

Bone formation around dental implants has been described as a combination of distance and contact osteogenesis (Davies, 2003). Distance osteogenesis outcomes from the surrounding bone that growth toward the implant surface whereas contact osteogenesis results from osteogenic cells that migrate along the implant surface to form new bone. In this study, the measurements of BS/TS have not shown significant differences in terms of distance osteogenesis between the two groups. However, the BIC values that are related to contact osteogenesis were significantly higher for TEST than for CONTROL implants at 4 weeks.

In addition, several studies have shown that the chemical composition of the surface may modulate the osseointegration of metal implants. Both the chemical composition and the surface energy of the implants have a positive influence on interfacial reactions and more specifically, bone formation (Vasak et al., 2014). However, without taking specific precautions, titanium surfaces tend to rapidly adsorb hydrocarbons from the environment which decreased surface energy. In this work, surface composition of the different implants as determined by XPS (Table 1) indicated that both implant surfaces were oxidized as titanium oxide and polluted with nitrogen and silicon probably resulting from the chemical etching, cleaning and grit-blasted processes. Interestingly, calcium and phosphorus were found on the TEST surface and the relative amount of calcium and phosphorus (63\% and $37 \%$, respectively) was in good agreement with the chemical composition of BCP particles used for grit blasting. BCP grit-blasting residues on surfaces may induce a beneficial effect at the bone-implant interface as HA and TCP materials are well known to be osteoconductive.

\section{5 | CONCLUSION}

In this pre-clinical study, dental implants with different surface characteristics were compared in terms of biocompatibility and osseointegration in mandible and maxillary of minipigs. Both surfaces of implants were roughened by calcium phosphate particles and etched in acids. After 4 and 12 weeks of implantation, both types of implants were non-irritating nor inflammatory for surrounding tissues and thus considered as biocompatible. Bone apposition on implants was significantly higher at 4 weeks for TEST in comparison with CONTROL dental implants while values were similar at latter time point. A faster osseointegration of the TEST than the CONTROL implants was therefore observed resulting from the nanostructure of the TEST surface.

\section{ACKNOWLEDGEMENTS}

Dr Marie-Francoise Heymann, MD anatomo-pathologist is greatly acknowledged for reading and scoring the histology sections. The authors would like to thank Julien de Lima for acquiring the BSEM images and for quantification of BIC and BS/TS $0.5 \mathrm{~mm}$. The authors are faithful to the Personnel of the CIRE platform, Gilles Gomot, Frederic Elleboult and Christian Moussu, for their help in anesthesia, pre- and post-operative care and euthanasia of animals.

\section{CONFLICT OF INTEREST}

This study was financially supported by the company Biotech Dental. The authors have, however, no conflict of interest with regards to the results of this study.

\section{AUTHOR CONTRIBUTIONS}

$\mathrm{AH}, \mathrm{LV}, \mathrm{RB}, \mathrm{JFM}$ and PL conceived the ideas and performed surgeries; GL and PL collected and analyzed the data; and AH and PL led the writing.

\section{ORCID}

Pierre Layrolle (iD https://orcid.org/0000-0001-9800-5210

\section{REFERENCES}

Alayan, J., Vaquette, C., Saifzadeh, S., Hutmacher, D., \& Ivanovski, S. (2017). Comparison of early osseointegration of SLA ${ }^{\circledR}$ and SLActive ${ }^{\circledR}$ implants in maxillary sinus augmentation: A pilot study. Clinical Oral Implants Research, 28(11), 1325-1333. https://doi.org/10.1111/clr.12988

Andrukhov, O., Huber, R., Shi, B., Berner, S., Rausch-Fan, X., Moritz, A., ... Schedle, A. (2016). Proliferation, behavior, and differentiation of osteoblasts on surfaces of different microroughness. 
Dental Materials, 32(11), 1374-1384. https://doi.org/10.1016/j. dental.2016.08.217

Balshe, A. A., Assad, D. A., \& Oral, S. E. J. O. (2009). A retrospective study of the survival of smoothand rough-surface dental implants. Retrieved from Ebscohost.com

Carmo Filho, L. C. D., Marcello-Machado, R. M., de Castilhos, E. D., Del Bel Cury, A. A., \& Faot, F. (2018). Can implant surfaces affect implant stability during osseointegration? A randomized clinical trial. Brazilian Oral Research, 32, e110. https://doi.org/10.1590/18073107bor-2018.vol32.0110

Citeau, A., Guicheux, J., Vinatier, C., Layrolle, P., Nguyen, T. P., Pilet, P., \& Daculsi, G. (2005). In vitro biological effects of titanium rough surface obtained by calcium phosphate grid blasting. Biomaterials, 26(2), 157-165. https://doi.org/10.1016/j.biomateria Is.2004.02.033

Davies, J. E. (2003). Understanding peri-implant endosseous healing. Journal of Dental Education, 67(8), 932-949.

Deporter, D. A., Watson, P. A., Pilliar, R. M., Chipman, M. L., \& Valiquette, N. (1990). A histological comparison in the dog of porous-coated vs. threaded dental implants. Journal of Dental Research, 69(5), 1138-1145. https://doi.org/10.1177/0022034590 0690050401

Doundoulakis, J. H. (1987). Surface analysis of titanium after sterilization: Role in implant-tissue interface and bioadhesion. The Journal of Prosthetic Dentistry, 58(4), 471-478. https://doi. org/10.1016/0022-3913(87)90279-4

Kim, Y.-H., Koak, J.-Y., Chang, I.-T., Wennerberg, A., \& Heo, S.-J. (2003). A histomorphometric analysis of the effects of various surface treatment methods on osseointegration. International Journal of Oral \& Maxillofacial Implants, 18(3), 349-356.

Le Guéhennec, L., Soueidan, A., Layrolle, P., \& Amouriq, Y. (2007). Surface treatments of titanium dental implants for rapid osseointegration. Dental Materials, 23(7), 844-854. https://doi.org/10.1016/j. dental.2006.06.025

Li, D., Liu, B., Han, Y., \& Xu, K. (2001). Effects of a modified sandblasting surface treatment on topographic and chemical properties of titanium surface. Implant Dentistry, 10(1), 59-64. https://doi. org/10.1097/00008505-200101000-00017

Lin, A., Wang, C. J., Kelly, J., Gubbi, P., \& Nishimura, I. (2009). The role of titanium implant surface modification with hydroxyapatite nanoparticles in progressive early bone-implant fixation in vivo. International Journal of Oral \& Maxillofacial Implants, 24(5), 808-816.

Louarn, G., Salou, L., Hoornaert, A., \& Layrolle, P. (2019). Nanostructured surface coatings for titanium alloy implants. Journal of Materials Research, 34(11), 1892-1899. https://doi.org/10.1557/jmr.2019.39

Mathieu, L., Mueller, T., Bourban, P., Pioletti, D., Muller, R., \& Manson, J. (2006). Architecture and properties of anisotropic polymer composite scaffolds for bone tissue engineering. Biomaterials, 27(6), 905916. https://doi.org/10.1016/j.biomaterials.2005.07.015

McCullough, J. J., \& Klokkevold, P. R. (2017). The effect of implant macro-thread design on implant stability in the early post-operative period: A randomized, controlled pilot study. Clinical Oral Implants Research, 28(10), 1218-1226. https://doi.org/10.1111/clr.12945

Mueller, W.-D., Gross, U., Fritz, T., Voigt, C., Fischer, P., Berger, G., ... Lange, K.-P. (2003). Evaluation of the interface between bone and titanium surfaces being blasted by aluminium oxide or bioceramic particles. Clinical Oral Implants Research, 14(3), 349-356. https://doi. org/10.1034/j.1600-0501.2003.00791.x

Philipp, A., Duncan, W., Roos, M., Hämmerle, C. H., Attin, T., \& Schmidlin, P. R. (2014). Comparison of SLA ${ }^{\circledR}$ or SLActive ${ }^{\circledR}$ implants placed in the maxillary sinus with or without synthetic bone graft materials-an animal study in sheep. Clinical Oral Implants Research, 25(10), 11421148. https://doi.org/10.1111/clr.12255
Piattelli, A., Manzon, L., Scarano, A., Paolantonio, M., \& Piattelli, M. (1998). Histologic and histomorphometric analysis of the bone response to machined and sandblasted titanium implants: An experimental study in rabbits. International Journal of Oral \& Maxillofacial Implants, 13(6), 805-810.

Poulos, N. M., Rodriguez, N. A., Lee, J., Rueggeberg, F. A., Schüpbach, P., Hall, J., ...Wikesjö, U. (2011). Evaluation of a novel calcium phosphate-coated titanium porous oxide implant surface: A study in rabbits. The International Journal of Periodontics \& Maxillofacial Implants, 26(4), 731-738.

Prasopthum, A., Cooper, M., Shakesheff, K. M., \& Yang, J. (2019). Threedimensional printed scaffolds with controlled micro-/nanoporous surface topography direct chondrogenic and osteogenic differentiation of mesenchymal stem cells. ACS Applied Materials \& Interfaces, 11(21), 18896-18906. https://doi.org/10.1021/acsami.9b01472

Rodríguez-Hernández, A. G., Juárez, A., Engel, E., \& Gil, F. J. (2011). Streptococcus sanguinis adhesion on titanium rough surfaces: Effect of shot-blasting particles. Journal of Materials Science: Materials in Medicine, 22(8), 1913-1922. https://doi.org/10.1007/ s10856-011-4366-8

Salou, L., Hoornaert, A., Louarn, G., \& Layrolle, P. (2014). Enhanced osseointegration of titanium implants with nanostructured surfaces: An experimental study in rabbits. Acta Biomaterialia, 11, 494-502. https://doi.org/10.1016/j.actbio.2014.10.017

Salou, L., Hoornaert, A., Stanovici, J., Briand, S., Louarn, G., \& Layrolle, P. (2015). Comparative bone tissue integration of nanostructured and microroughened dental implants. Nanomedicine (London, England), 10(5), 741-751. https://doi.org/10.2217/nnm.14.223

Vasak, C., Busenlechner, D., Schwarze, U. Y., Leitner, H. F., Munoz Guzon, F., Hefti, T., ... Gruber, R. (2014). Early bone apposition to hydrophilic and hydrophobic titanium implant surfaces: A histologic and histomorphometric study in minipigs. Clinical Oral Implants Research, 25(12), 1378-1385. https://doi.org/10.1111/ clr.12277

Wennerberg, A., \& Albrektsson, T. (2000). Suggested guidelines for the topographic evaluation of implant surfaces. International Journal of Oral \& Maxillofacial Implants, 15(3), 331-344.

Wennerberg, A., \& Albrektsson, T. (2009). Effects of titanium surface topography on bone integration: A systematic review. Clinical Oral Implants Research, 20(Suppl. 4), 172-184. https://doi. org/10.1111/j.1600-0501.2009.01775.x

Wennerberg, A., \& Albrektsson, T. (2010). On implant surfaces: A review of current knowledge and opinions. International Journal of Oral \& Maxillofacial Implants, 25(1), 63-74.

Yurttutan, M. E., \& Keskin, A. (2018). Evaluation of the effects of different sand particles that used in dental implant roughened for osseointegration. BMC Oral Health, 18(1), 47. https://doi.org/10.1186/ s12903-018-0509-3 